\title{
Vibration-based tool life monitoring for ceramics micro- cutting under various toolpath strategies
}

\author{
Zsolt J. Viharos ${ }^{1,3}$, László Móricz², Máté Büki ${ }^{1}$ \\ ${ }^{1}$ Centre of Excellence in Production Informatics and Control, Institute for Computer Science and Control (SZTAKI), Eötvös Loránd Research \\ Network (ELKH), Kende u. 13-17., H-1111, Budapest, Hungary \\ 2 Zalaegerszeg Center of Vocational Training, Kinizsi Pál utca 74., H-8900, Zalaegerszeg, Hungary \\ 3 John von Neumann University, Izsáki u. 10., H-6000, Kecskemét, Hungary
}

\section{ABSTRACT}

The 21st century manufacturing technology is unimagined without the various CAM (Computer Aided Manufacturing) toolpath generation programs. The aims of developing the toolpath strategies which are offered by the cutting control software is to ensure the longest possible tool lifetime and high efficiency of the cutting method. In this paper, the goal is to compare the efficiency of the 3 types of tool path strategies in the very special field of micro-milling of ceramic materials. The dimensional distortion of the manufactured geometries served to draw the Taylor curve for describing the wearing progress of the cutting tool helping to determine the worn-in, normal and wear out stages. These isolations allow to separate the connected high-frequency vibration measurements as well. Applying the novel feature selection technique of the authors, the basis for the vibration based micro-milling tool condition monitoring for ceramics cutting is presented for different toolpath strategies. It resulted in the identification of the most relevant vibration signal features and the presentation of the identified and automatically separated tool wearing stages as well.

\section{Section: RESEARCH PAPER}

Keywords: Ceramics; micro-milling; tool wear; machining strategy; vibration analysis; feature selection

Citation: Zsolt János Viharos, László Móricz, Máté István Büki, Vibration-based tool life monitoring for ceramics micro-cutting under various toolpath strategies, Acta IMEKO, vol. 10, no. 3, article 18, September 2021, identifier: IMEKO-ACTA-10 (2021)-03-18

Section Editor: Lorenzo Ciani, University of Florence, Italy

Received February 5, 2021; In final form September 9, 2021; Published September 2021

Copyright: This is an open-access article distributed under the terms of the Creative Commons Attribution 3.0 License, which permits unrestricted use, distribution, and reproduction in any medium, provided the original author and source are credited.

Funding: This work was supported by the European Commission through the H2020 project EPIC (https://www.centre-epic.eu/) under grant No. $739592 . ;$ by the Hungarian ED_18-2-2018-0006 grant on a "Research on prime exploitation of the potential provided by the industrial digitalisation"; by the Ministry of Innovation and Technology NRDI Office within the framework of the Artificial Intelligence National Laboratory Program, Hungary.

Corresponding author: Zsolt János Viharos, e-mail: viharos.zsolt@sztaki.mta.hu

\section{INTRODUCTION}

Machining of rigid materials with regular cutting-edge geometry is one of the main trends in the 21st century. Ceramics are such rigid materials that are employed more and more widely as raw materials thanks to their high hardness and thermal resistance [1], [2]. There are various options for machining them, e.g. using water, laser or abrasive grinding [3], [4], [5], however, their high costs and complex setups are important drawbacks of these technologies. Therefore, the machining of ceramics with a classical, regular cutting-edge geometry is still a promising solution, however, considering the relative quick wearing process of the cutting tool without an appropriate technological optimization, this methodology will be economically not acceptable. Optimizing a technology is typically a multicriteria assignment, like here, the main aim is to find the smallest production cycle time, and at the same time the tool life has to be maximal, too. The effect of technology parameters on tool life has been investigated in several of the authors' previous articles [6], [7], [8].

An important part of tool life analysis is the investigation of vibrations generated during cutting method. The relative vibration between the micro-milling cutter and workpiece influences the processing quality and tool life [9]. Frequency spectrum analysis was executed to establish for example the tool wear and chatter frequency characterization. Based on this method, of the cutting process that are clearly not visible in the time domain can be revealed [10]. To determine the source of chatter or other dominant tool wearing frequencies, proper selection of the critical dynamic force signatures is required to perform frequency or power spectrum analysis. Dimla and Lister [11] identified for turning that the tangential force components 
act on the rake face insert and both cutting forces and vibration signatures were most sensitive to tool wear. Youn and Yang [12] differentiated cutting force components to detect the difference between flank and crater wear for varying machining conditions in turning. Work by Sarhan et al. [13] involving the use of a 4flute end mill on steel of $90 \mathrm{BHN}$ indicated that the magnitudes of the first harmonics of cutting force frequency spectrum increased significantly with increase in tool flank wear, feed per tooth and axial depth of cut. Elbestawi et al. [14] also had similar observations when face milling of AISI 1020 steel and aluminium alloy. The deterioration in tool wear increases the tool chip and tool workpiece contact areas and these in turn cause an increase in friction, too. A worn tool generates high frequency tonal vibrational energy that does not arise in a new tool [15] Consequently, the noise emitted in the area is amplified [16]. Tonshoff et al. [17] employed the use of acoustic emission signals to determine the influence of a hard turning process on the sub surface microstructure of the workpiece. The results obtained showed that the amplitude of the frequency analysis increased with increasing flank wear due to an enlarged contact area.

One of an appropriate complement for vibrational analysis is the application of a neural network-based method. Qi Yao et al. [9] examined the relationship between cutting force amplitude, frequency and vibration displacement and it is ascertained by using a neural network method. The scientific literature mirrors that vibration signal analysis forms an increasing trend among the tool wear monitoring methods.

In this paper, the effect of toolpaths generated by CAM software on the tool lifetime is examined. The three most popular tool paths (strategies: wave form, cycloid, chained) are analysed as described in the next three sections.

\subsection{Wave form path}

The wave form tool path (Figure 1) for milling technology results that the tool is working with constant tool diameter sweep. The contact angle along the toolpath has a direct effect on the cutting forces. By adjusting the contact angle, the cutting force can also be controlled. Owing to this the tool load is constant in every changing direction during the machining through avoiding sharp changes in direction, which couldn't be found among the average path generation methods [6], [19].

The other advantage of the wave form strategy is that the value of material removal speed is kept constant, that is different

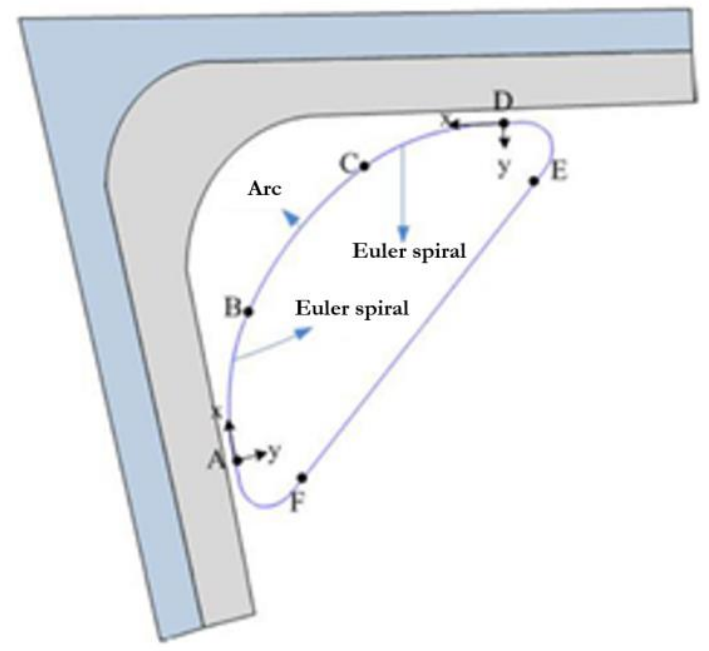

Figure 1. Element of waveform path [18]. form the other path generation methods. Cutting distributes wear evenly along the entire flute length, rather than just on one tip. The radial cutting depth is reduced to ensure consistent cutting force, allowing cutting material escaping from the flutes. So, tool lifetime is further extended as most of the heat is removed in the chip.

\subsection{Cycloid path}

The essence of the cycloid path strategy is to move the tool on a circle with the largest possible radius, thus reducing the kinematic contact (and tool load) (Figure 2).

The cycloid form is a milling technology where the tool milling is going along an arc, avoiding sharp changes in the direction. Although it does not control the tool, this strategy also can reduce the tool load, and the roughing strategy is optimized easier [6], [8]. The problem with the average toolpath is that tool load increases significantly in the corners requiring shallower depths of cut and reduced feed. This problem can be avoided with cycloid and wave form path. Because the pocket was used during the experiment did not have circle geometry, so the technology was made optimized with entremets. The entremets is an option in the software with which the tool load can be reduced in the corner. By choosing the correct stepover, the contact angle can be kept at a specified level. Another advantage of the strategy is that high feeds along some paths cab be achieved.

\subsection{Constant stepover toolpaths (Chained path)}

Most software are usually capable of creating constant stepover toolpaths, contour-parallel, and direction-parallel paths, but these algorithms do not focus on machining parameters but only on material removal [20].

During the generation of the constant stepover path (chained path), the cutting tool removes the material moving back and forth on the horizontal plane within each $\mathrm{z}$ (vertical) level (Figure 3). The strategy uses both directional and indirectional milling technology, leading to poor surface quality and short tool life.

\section{EXPERIMENTS FOR THE MACHINING OF CERAMICS}

The setup for the experiments is presented in Figure 4. One of the main aims is to follow the wearing process of the micromilling tool during machining of ceramics and to compare it in an offline mode against the geometrical changes (length, width and depth of features) of the machined ceramic workpiece. Another goal is to using high-frequency online vibration

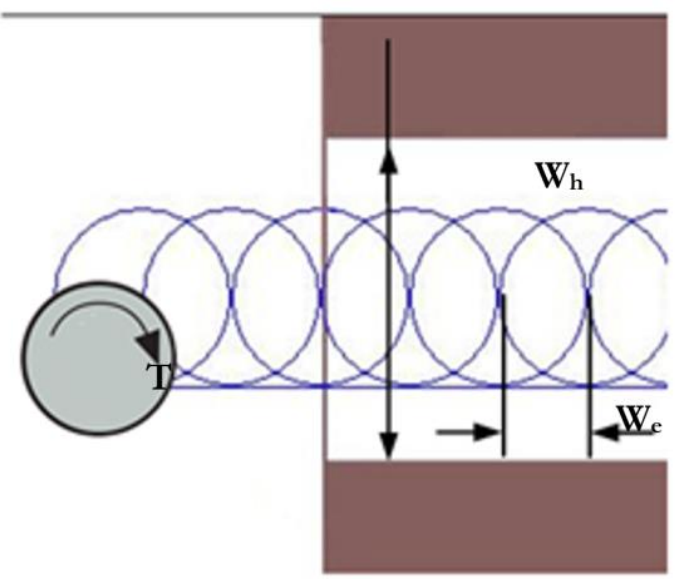

Figure 2. Cycloid toolpath [20]. 

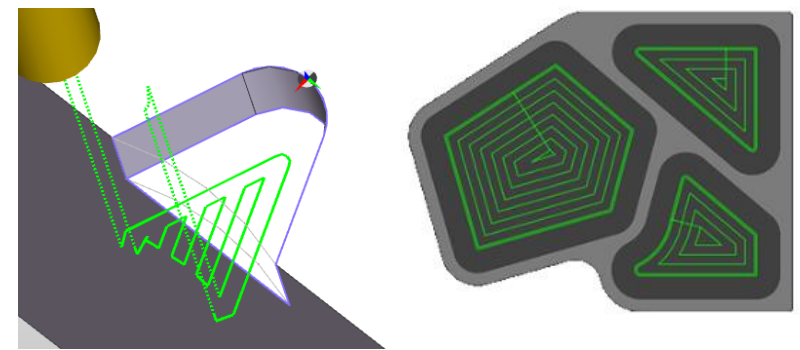

Figure 3. Contour-parallel, and direction-parallel stepover toolpaths (chained path).

measurement online, during the cutting process on the other hand.

Connections between the wearing stages and the measured online and offline parameters were determined using a selfdeveloped, artificial neural network-based feature selection solution.

\subsection{Parameters of the milling machine}

The basis of the experiments was the milling machine that was planned and built by the CncTeamZeg group. It is operated in Zalaegerszeg (Figure 4), Hungary. During the planning, the aim was to cut metal material but the preliminary calculations and tests on ceramic material removal proved that it is able to cut ceramic material as well.

\section{INDIRECT, OFF-LINE TOOL WEAR DETECTION MEASURING THE PRODUCED WORKPIECE GEOMETRY}

During the cutting process, microscopic images were taken repeatedly after a certain number of workpiece machining in order to monitor in an offline way the wearing evolution of the tool on workpiece geometry. Measurements were performed using Zeiss Discovery V8 microscope and the wearing in the pictures were evaluated by the authors.

Beyond the microscopic control of the cutting tool geometry the changes resulted by the tool wear on the machined workpiece was also measured. These dimensional changes of the manufactured geometries are summarized in Figure 5. During the measurements, changes in the width, length and depth of the geometries were examined. The applied technology settings (axial depth of cut, radial depth of cut, cutting speed, feed rate) were the same in all three cases, only the machining paths (strategies: wave form, cycloid, chained) were varied.

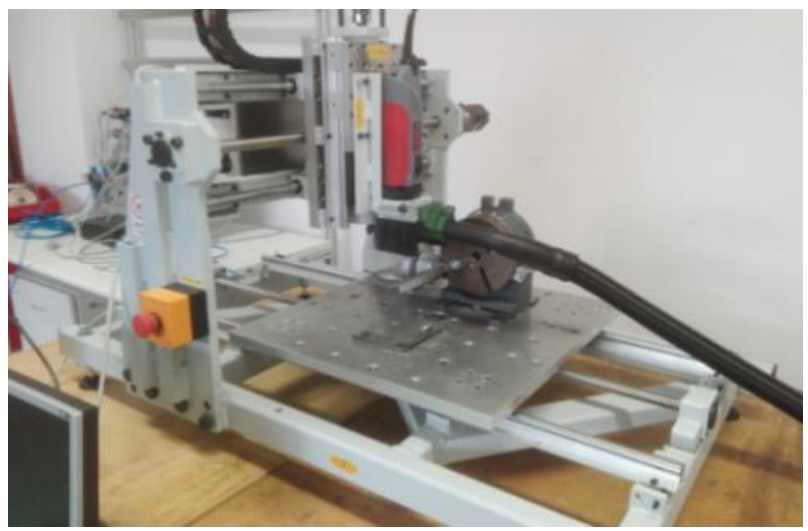

Figure 4. The applied CNC machine, detailed parameters are in [8].

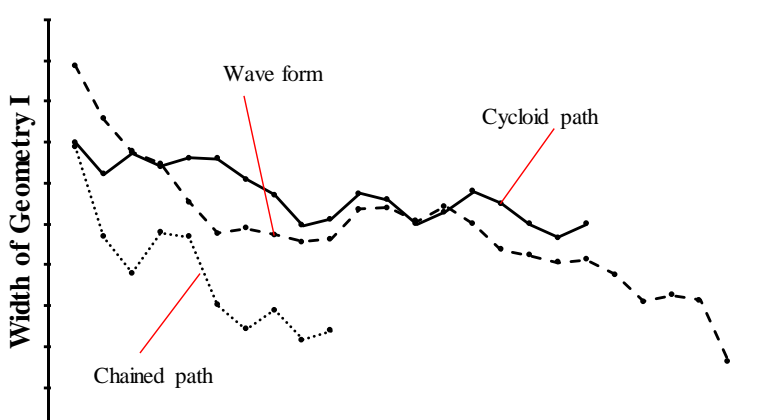

Number of machined workpieces

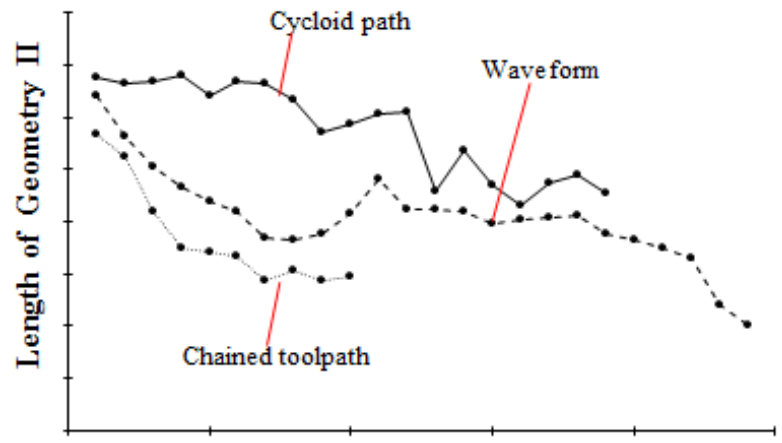

Number of machined workpiece

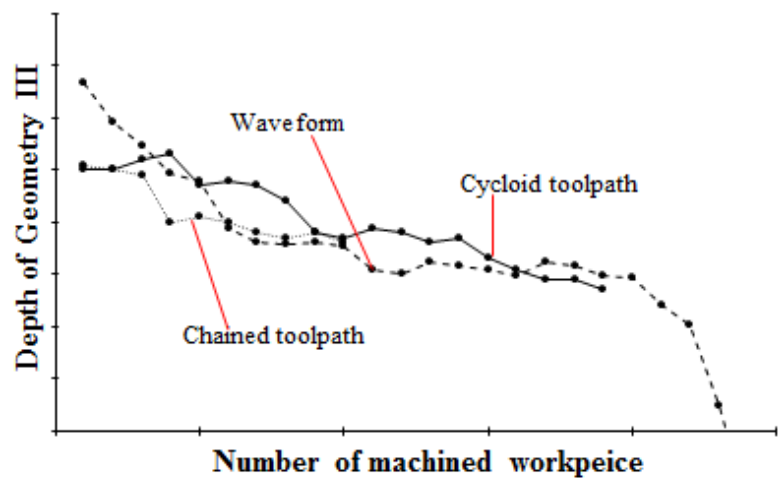

Figure 5. Changes in the Geometry I.- II. and III. of the machined geometries for the Wave form, Cycloid and Chained tool path.

These workpiece measurements represent clearly a complete and valid cutting tool life curves (Taylor curves) and various variable conclusions can be drawn from them:

- It can be seen in Figure 5 that the tool lifetime achieved using chained toolpath is nearly half of the tool lifetime achieved using the wave form and cycloid tool path.

- During the application of the chained path, a tool break occurred early, under the machining of the 11 th set.

- At the cycloid tool path, exponential tool wear and tool break were observed in 20th set.

- Using the waveform path, the manufacturing time of one feature was $57 \%$ longer than in the case of the chained toolpath.

- With the cycloid path, the manufacturing time of a feature was nearly five times more than at the chained tool path.

- Considering the tool lifetime and the manufacturing time, the waveform seems to be the most economical toolpath strategy during ceramic machining. 


\section{DIRECT, ON-LINE TOOL WEAR ANALYSIS USING VIBRATION MEASUREMENTS}

The scientific literature mirrors that Acoustic Emission (AE) signals form an increasing trend in the same way as the increase of the tool wear analysis in metal cutting but it is not evident for micro-milling of ceramics.

In [21], Bhuiyan et al. pointed out: the increase in the tool wear increases the tool-workpiece contact area and friction coefficient, as well. In another experiment, the opposite, so, the decrease in the vibration amplitudes were detected during measurements, in metal cutting field. In the paper of the authors, they reported a similar phenomenon during ceramic machining as well [8]. Based on the results of the measurements, decrease in the vibration amplitudes were detected during the wear evolution of the tool, consequently, the contact surfaces between the cutting tool and workpiece became smaller during the wearing of the tool for ceramics milling, mainly because of the complex and multiplicative wearing forms. The related frequency analysis showed that the wear-out process of the tool resulted also in a shift of the dominant frequencies into higher frequency ranges.

In this research, the authors supplemented the results of the previous paper [8] with an AE study on various toolpath strategies. In the reported previous research, vibration measurement of ceramics milling was established with a sampling frequency of $100 \mathrm{kHz}$ measuring in one direction. Instead of analysing over millions of individual measured values, as time series of the vibration amplitudes, several descriptive features (e.g., statistical measures, like amplitude, standard deviation, 3rd moment, etc.) were calculated. Such a feature vector was calculated for each workpiece/machining process, while during the experiments the same tool is used, until the tool wear-out, or tool break.

Feature selection was applied to find the most descriptive features for distinguishing three typical different stages of the tool life. For this division, in the first step, the tool wear curve was determined from the geometry produced on the workpiece by an indirect method (based on the workpiece geometries measured). After this, the curves were divided into three sections depending on the wear phase of the tool and the degree of geometry reduction (worn-in, normal, wear-out (or brake).

\subsection{Micro-cutting tool wearing stages}

In contrast to the previous research [8], not the changes of parameters of the geometry (width, length, depth) were analysed, but the volume changes calculated from the geometries obtained by each toolpath strategy (Figure 6).

During the analysis of the graphs, 3 well-separable sections of the Taylor curve were observed for the waveform graph (worn in-tool, normal condition, worn out). In contrast, in the cycloid path, no significant tool wear was observed until a certain geometry was manufactured (period "A"), followed by steep but uniform tool wear (period "B"). At the chained toolpath, the rapid wear process (period " $A$ ") as well as the normal wear condition (period "B") were observed, however, the tool was already broken at the very beginning of the wear out phase (period “C”).

\subsection{Most descriptive, direct vibration signal behaviour in respect to the micro-cutting tool wear-out}

After running the feature selection method, called Adaptive, Hybrid Feature Selection (AHFS) developed by some of the authors [22], the variables/features (calculated based on the
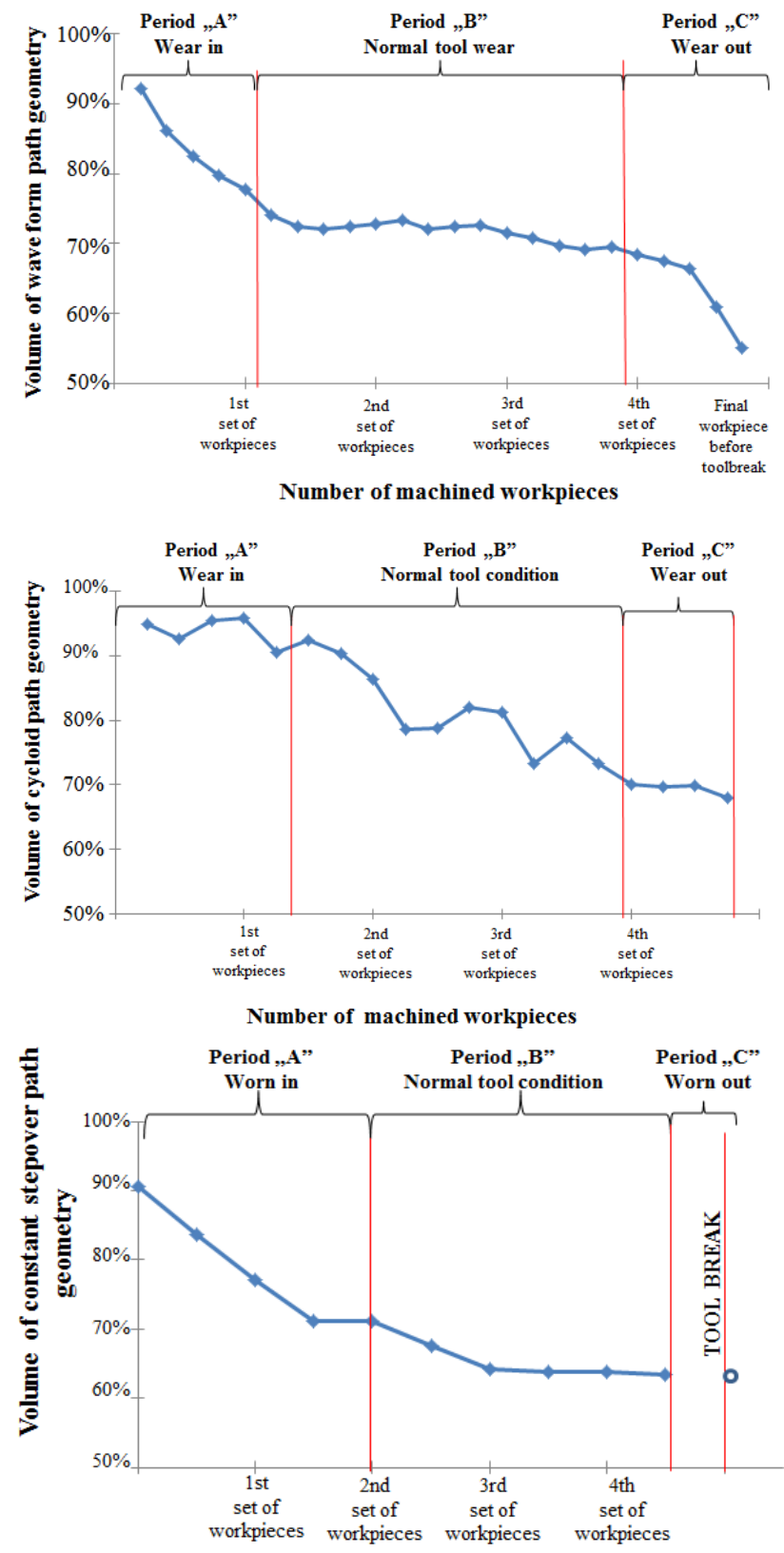

Number of machined workpieces

Figure 6. Changes in the volumes of the manufactured geometries for the Wave form (upper), Cycloid tool path (middle) and Stepover (Chained bottom) tool path.

vibration signal) that most accurately describe the change in three stages of the Taylor curve were determined. It has to be mentioned that the feature selection identifies the first, so called most informative feature, however, the second one serves with the additional most informative one, etc., consequently, the features are not independent, it is really important for the evaluation of their meaning and effects.

Selected features for the waveform strategy:

- Number of the times the signal crosses its mean value

- Standard deviation

- Fourth momentum - kurtosis

Having identified the most informative features calculated from the measured vibration signal, their evolution along the wearing progress can be presented, partly for engineering validation of the results of the mathematical algorithm. The 
progress in the values of the three, selected vibration signal features are presented along the wearing stages of the cutting tool in Figure 7.

The first identified variable name of "Number of times the signal crosses its mean value" describes the intersection density of the $\mathrm{X}$ axis of the vibration signal. In the stage of wear-in (Period " $A$ ") the curve is at a high level, but there is a continuous decrease. This means that the tool vibrates at a high frequency in the initial stage. In the normal wearing (Period "B") phase, the signal oscillated at a lower frequency compared to the " $A$ " phase. In the wear-out (Period C) phase, there was a further decrease in the number of $\mathrm{X}$-axis incisions.

The second feature identified was the standard deviation. The standard deviation showed similar change to the previous variable. In the wear-in period (Period " $A$ "), the signal shows large variance. In the normal period of tool lifetime (Period "B"), there was a decreasing trend of the standard deviation. In the period of wear out (Period "C"), the standard deviation of the signal showed a drastic decrease.
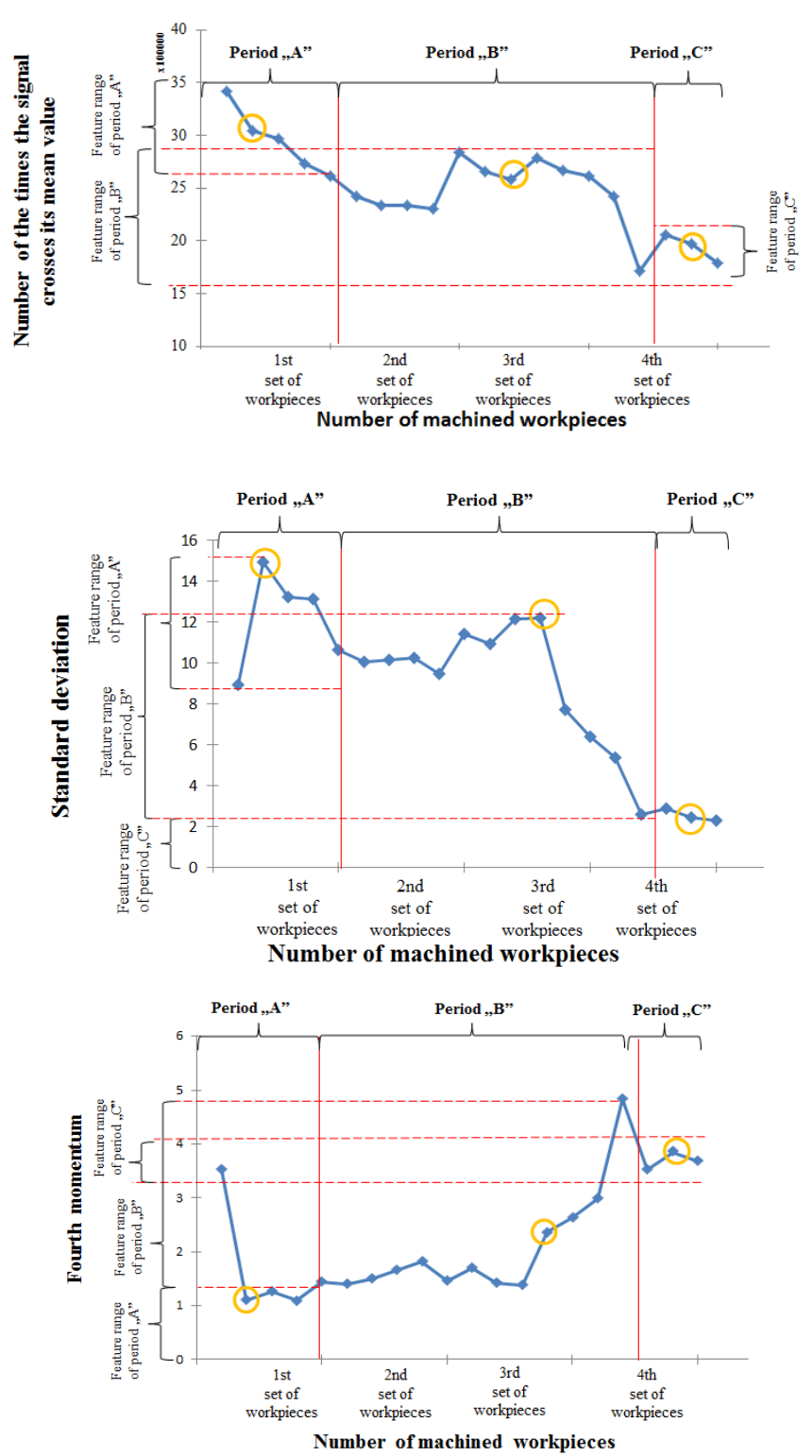

Figure 7. Selected changes in the vibration signal behaviour at waveform strategy: "Number of the times the signal crosses its mean value "- "Standard deviation" - "Fourth momentum" along the tool live-cycle.
The third parameter identified is the fourth momentum, also called as kurtosis. The fourth momentum describes the distribution-flatness of the signal. In the case of a sharp tool, the kurtosis follows a flat trend, while in the case of a worn tool, the distribution curve takes on an increasingly sharper shape.

Selected features for the gycloid strategy:

- Number of the times the signal crosses its mean value

- Mean value

- Second momentum.

The progress in the values of the three, selected vibration signal features are presented along the wearing stages of the cutting tool in Figure 8.

Selected features for the chained strategy:

- Mean value

- Fourth momentum

- Number of the times the signal crosses its mean value.

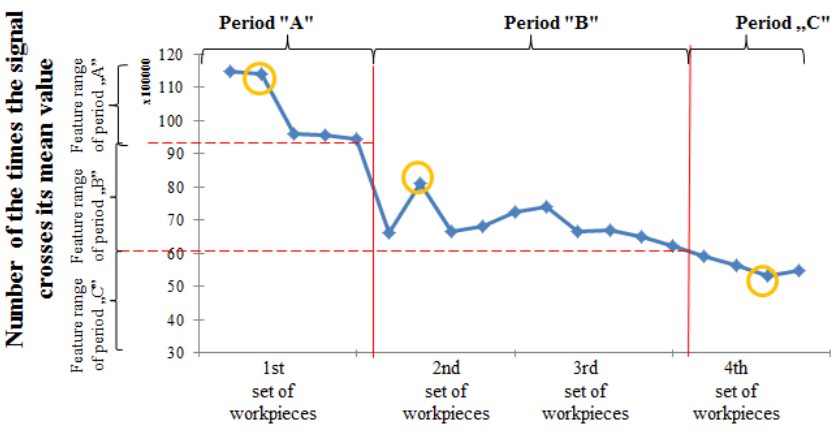

Number of machined workpieces
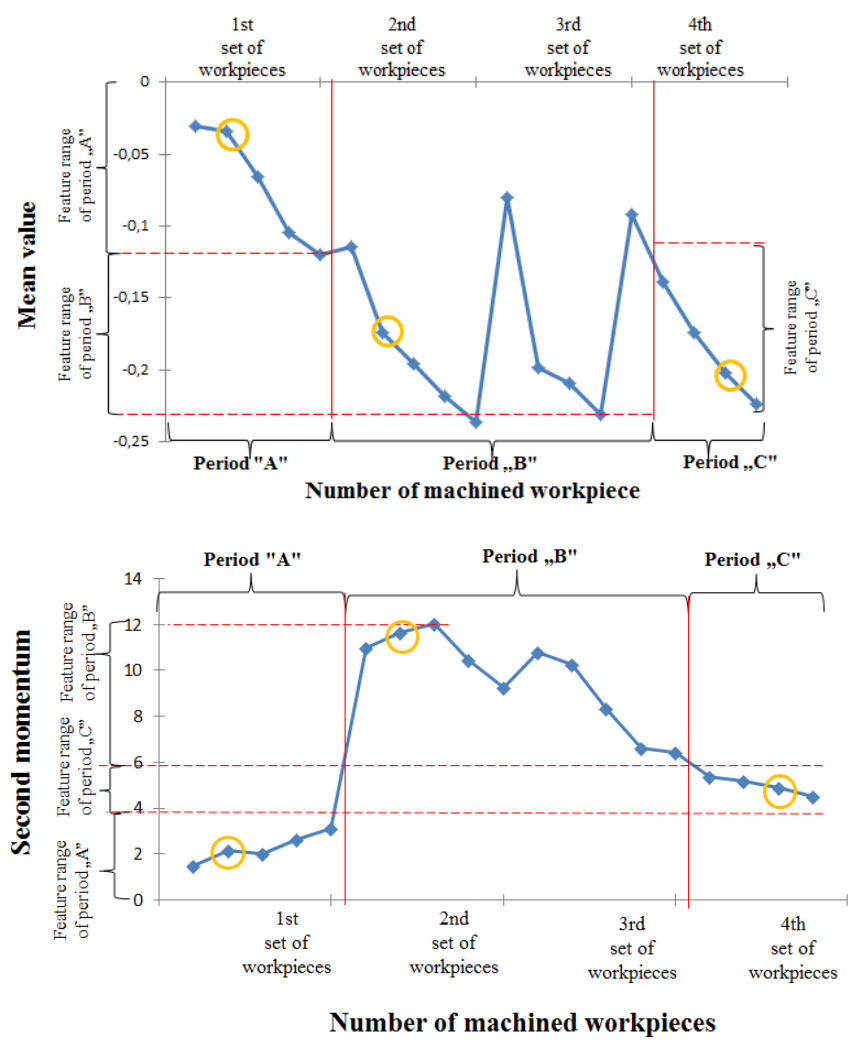

Figure 8. Selected changes in the vibration signal behaviour at the cycloid strategy: "Number of the times the signal crosses its mean value "- "Mean value" - "Second momentum" along the tool live-cycle. 

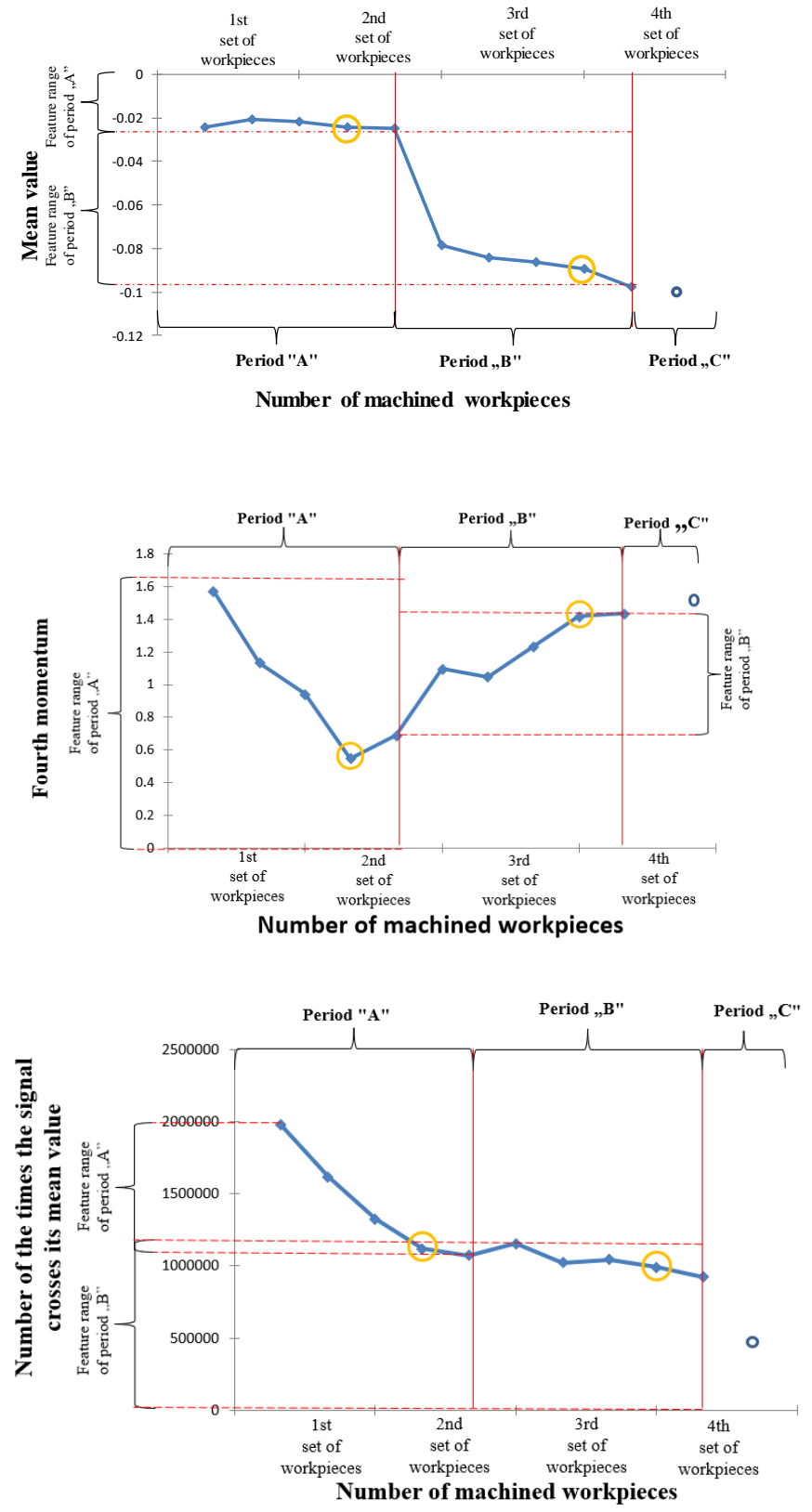

Figure 9. Selected changes in the vibration signal behaviour at the chained strategy: Mean value - Fourth momentum - Number of the times the signal crosses its mean value along the tool live-cycle.

The progress in the values of the three, selected vibration signal features are presented along the wearing stages of the cutting tool in Figure 9.

\subsection{Most descriptive vibration signal behaviour in frequency domain in respect to the micro-cutting tool wear-out}

The vibrations are stochastic signals because they represent temporal processes where parts of the phenomenon are characterized by probability variables (ceramic material inhomogeneity, asymmetric wear of tool edges, factors that cannot be described in an exact way in the micromachining process, white noise, etc.). In case of the power density (PSD), the power of the signal per unit frequency range is calculated. In the analysis of the PSD functions, the goal is to use the feature selection method to find those PSD frequency components where the individual sections of the curve are clearly separated from each other based on the separated stages of the Taylor

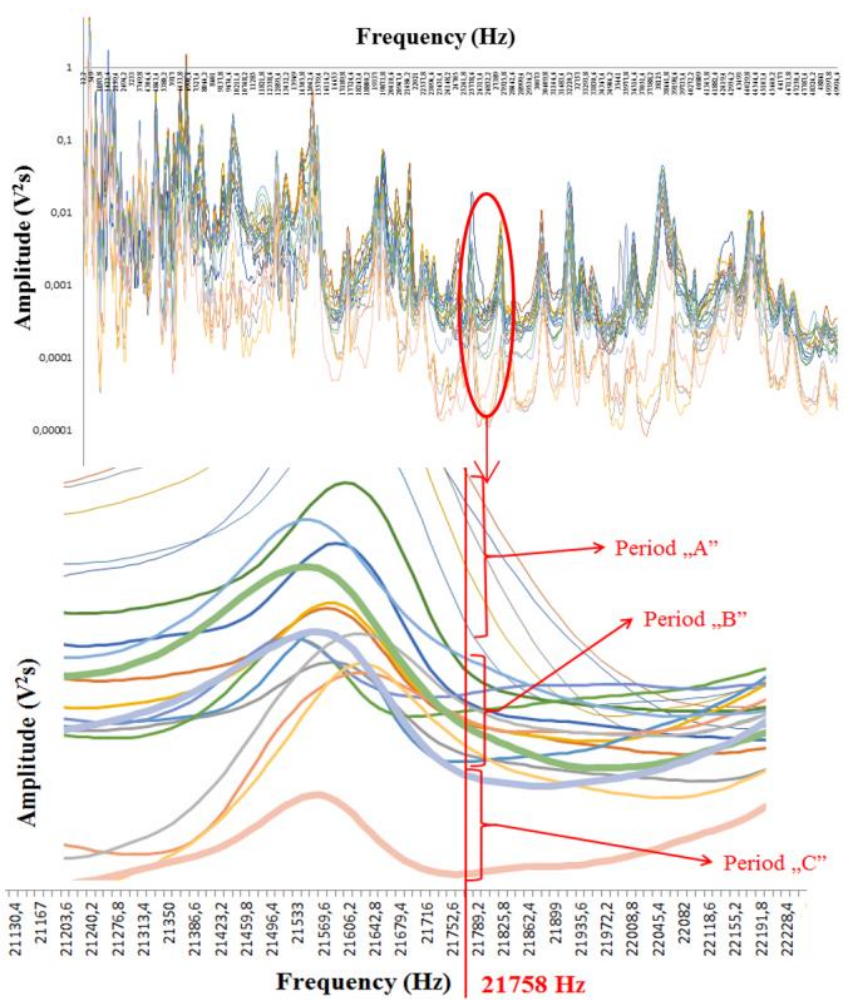

Figure 10. Separation of the stages of wear-in (thin curves), normal wear condition (middle thick curves) and wear-out (thick curves) tool according to the waveform strategy.

curve. Feature selection results showed that the highest separation of the three ranges occurs at $21758 \mathrm{~Hz}$ (Figure 10) using the waveform strategy.

Figure 10 shows that the ranges are separated at the analysed frequency applying the cycloid strategy. In the stage of wear out (Period "C"), two recorded data sets were damaged during the measurements, so they cannot be considered in the analyses. Therefore, only three curves are visible in range of wear out period.

At the examined frequency $(21758 \mathrm{~Hz})$, a continuous decrease in amplitude is observed, which indicates a decrease in the contact surface of the tool and the workpiece (Figure 11).

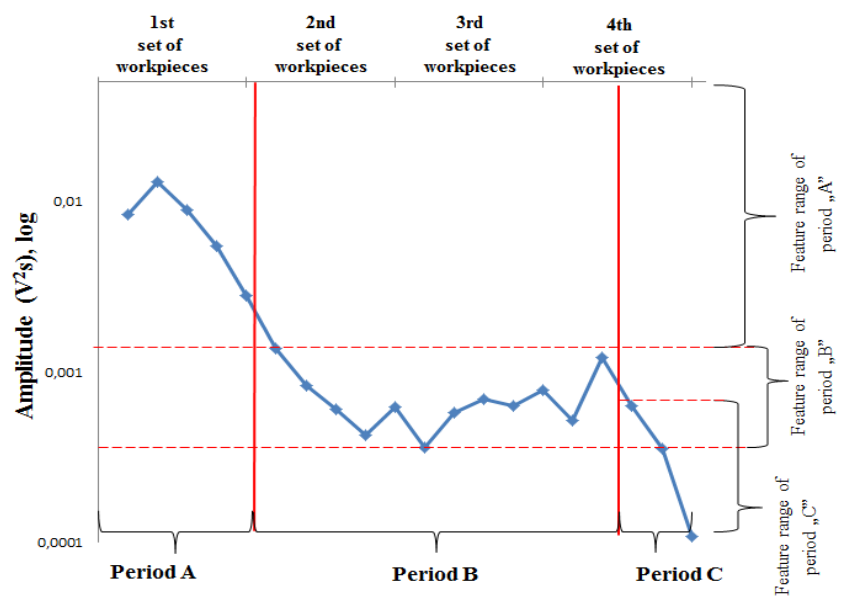

Figure 11. Variation of PSD amplitude values along the manufactured workpieces at $21758 \mathrm{~Hz}$ at the waveform strategy. 


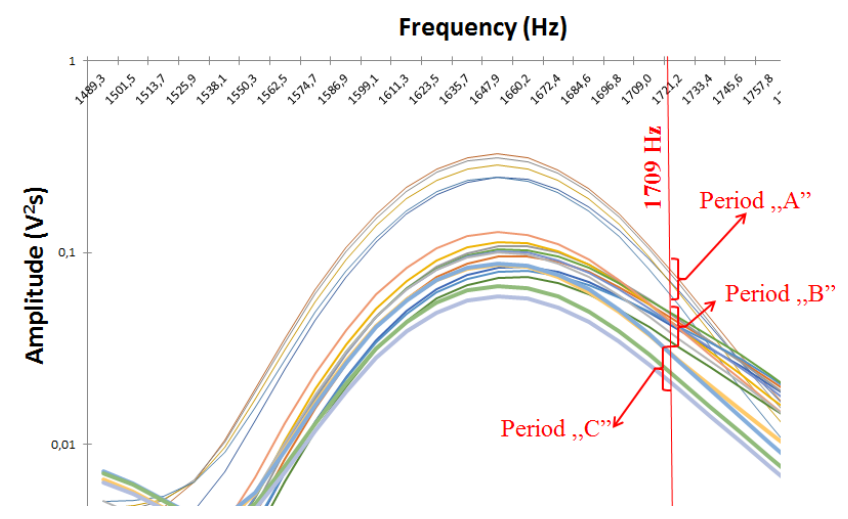

Figure 12. Separation of the stages of wear-in (thin curves), normal wear condition (middle thick curves) and wear-out (thick curves) tool according to the cycloid toolpath.

The next toolpath examined was the cycloid strategy. Here, the results showed that the separation of the ranges should be sought at $1709 \mathrm{~Hz}$ as summarized in Figure 12.

Like at the waveform, a continuous decrease in amplitude is observed at the cycloid strategy.

The last toolpath examined was the chained strategy. Here, the results showed that the separation of the ranges should be sought at $2796 \mathrm{~Hz}$ as presented in Figure 14.

In Figure 13, the three ranges are well separated at the frequency obtained by the feature selection. In the case of the chained toolpath, based on the volume analysis of the pocket, the geometry of the last pocket did not differ significantly from the size of the previous pocket. However, tool break occurred in the pocket after the last one presented, so, in the labelling, the last pocket was classified to the range of the wear-out period. It can be seen in Figure 15 that the $8^{\text {th }}$ point jumps out, so, in this way the last data point (representing alone the wear-out stage) overlaps with the normal stage. Based on this, it can be concluded that the tool breakage was not only caused by the tool wearing.

A similar phenomenon can be observed for the waveform path (Figure 10), where the amplitude measured at the last geometry of the Taylor curve is included into the normal tool wear range. However, determining the cause of the fractures requires further investigations.

In contrast to the previous toolpath strategies, an opposite, increasing amplitude value trend was observed along the machining, applying the chained toolpath (Figure 15).

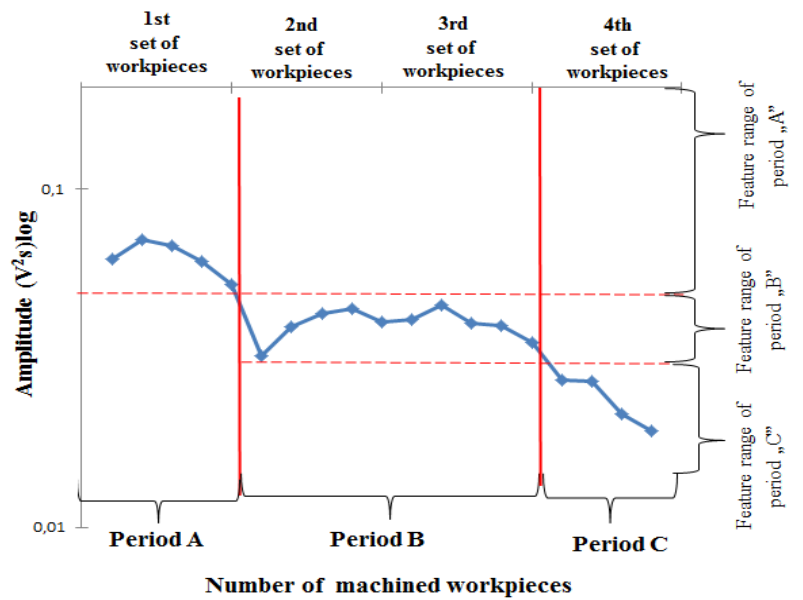

Figure 13. Variation of PSD amplitude values along the manufactured workpieces at $1709 \mathrm{~Hz}$ at the cycloid strategy.

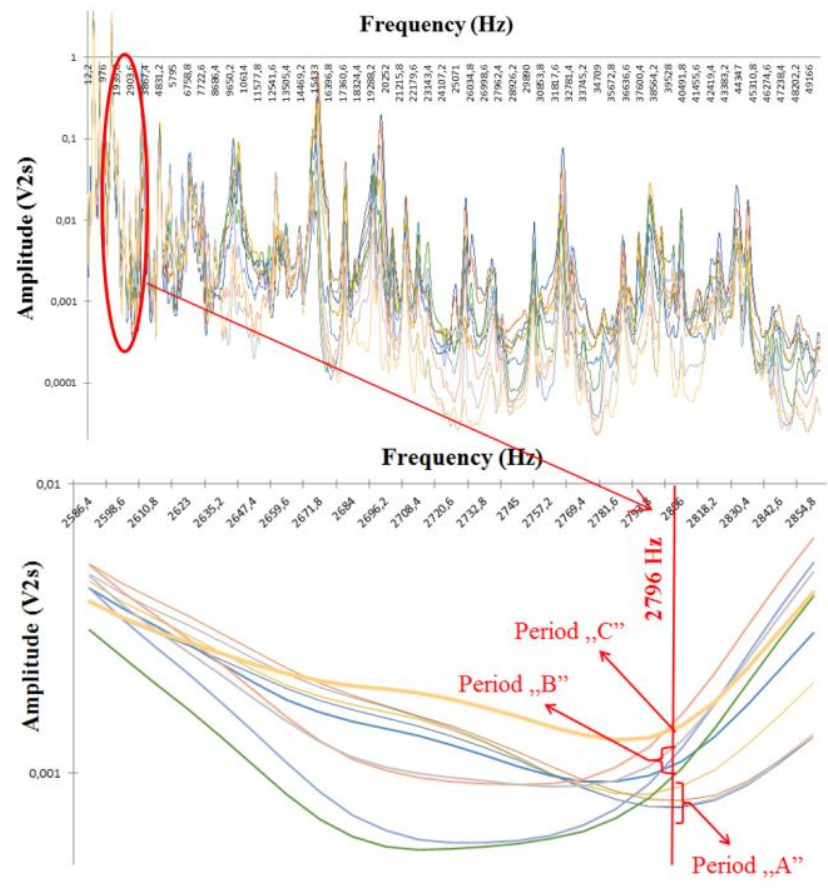

Figure 14. Separation of the stages of wear-in (thin curves), normal wear condition (middle thick curves) and wear-out (a thick curve) tool according to the chained toolpath.

\section{VALIDATION AND REPRESENTATION OF THE FOUNDINGS ACCORDING TO THE ORIGINAL, MEASURED VIBRATION SIGNAL CURVES}

For the engineering-oriented validation and representation, some original vibration measurements for the selected experiments marked as yellow circles on the Figure 7, Figure 8 and Figure 9 (put into the different stages on the identified, important feature curves of the waveform, cycloid and chained toolpaths, respectively) are presented in a tabular form in Figure 16. It mirrors clearly that the presented methodology works appropriately, the differences between the three tool wear stages mirror the identified behaviours, consequently, there is an open floor for realizing the vibration-based monitoring and supervision of the micromilling of ceramics.

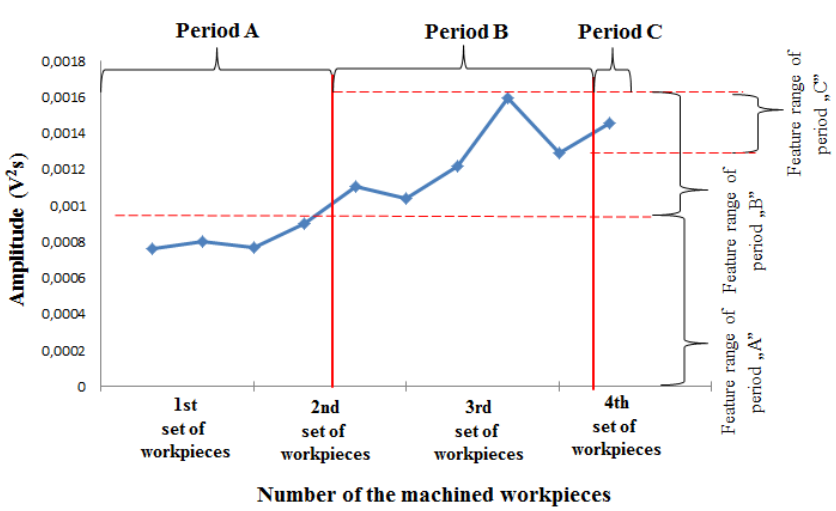

Figure 15. Variation of amplitude values along the manufactured workpieces at $2796 \mathrm{~Hz}$ using the chained toolpath. 


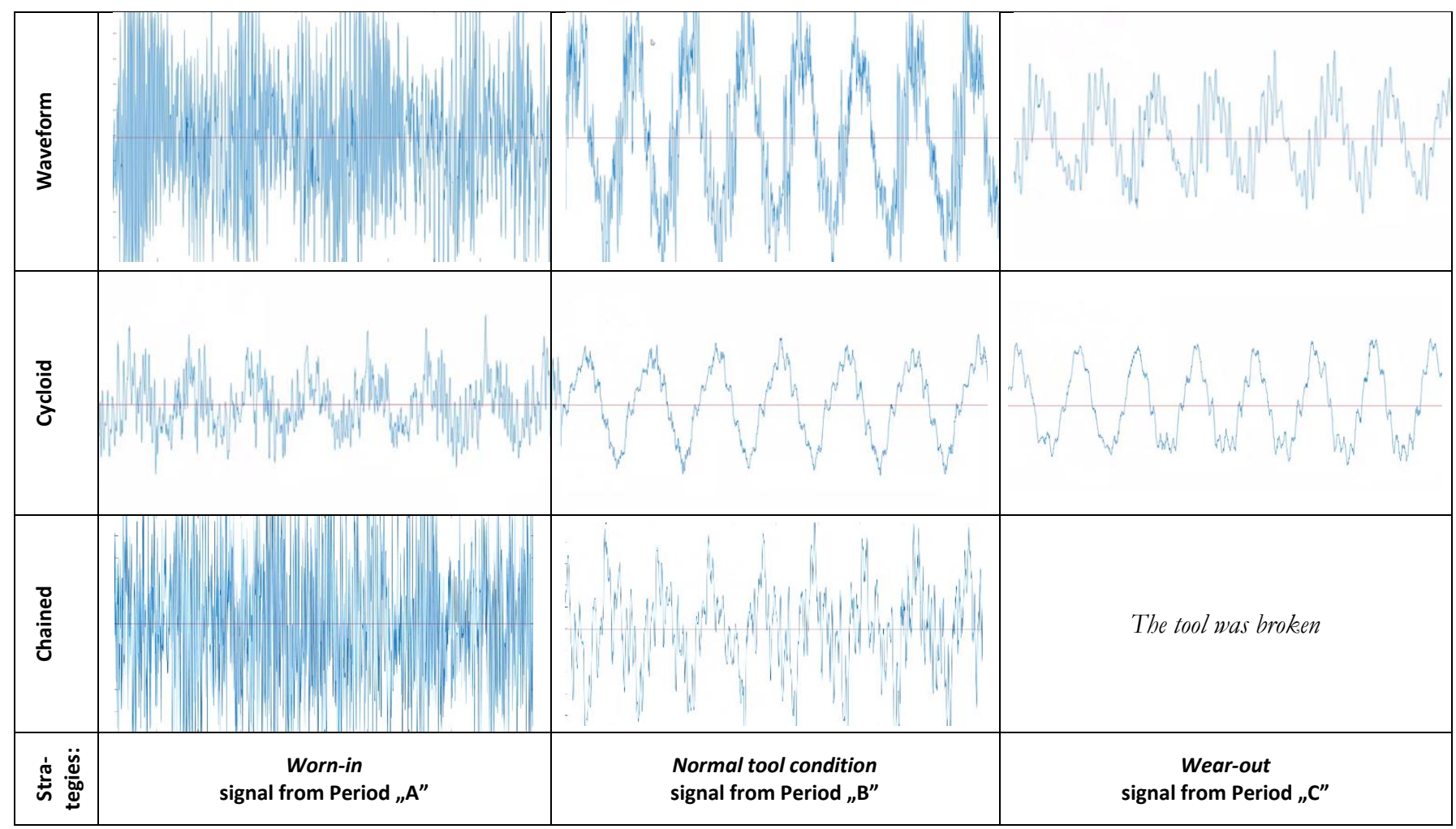

Figure 16. Vibration signal examples representing the progress at different tool wearing stages (worn-in, normal condition, wear-out) using the three analysed toolpath strategies (Waveform, Cycloid, Chained).

\section{CONCLUSIONS AND OUTLOOK}

In this paper, tool wear monitoring was investigated using direct and indirect methods to compare three CAM path strategies (waveform, cycloid and chained). The key conclusions of the paper are:

- The results represents clearly that the introduced methodology works well; it was found that the most relevant signal features and the original, "pure" signal measurements mirrors the identified behaviour, consequently, there is an open floor for realizing vibration-based monitoring and supervision of the micro-milling of ceramics.

- The appointed features of the vibration signals describe the three typical stages (worn-in, normal, wear-out) of the tool life cycle according to the Taylor curve identified.

- In general, the feature "Number of the times the signal crosses its mean value" has the highest relevance based on the vibration signal, so, this measure describes in the most accurate way the tool wearing progress.

- Using the feature selection method, it was possible to find the frequencies where the individual regions of the Taylor curves are well separated from each other.

- Applying the introduced method, it is possible to determine the actual wear of the cutting tool by analysing the vibration frequencies at micromilling of ceramics.

As research outlook, more detailed, novel tool wearing symptoms will be analysed in the future, the milling process/tool path will be split up into individual, homogenous, much smaller sections (layers and curves \& linear movements) and so, a more sensitive and more detailed process monitoring will be possible, moreover different types of tool wearing will be considered separately.

\section{ACKNOWLEDGEMENT}

This work was supported by the European Commission through the H2020 project EPIC (https://www.centre-epic.eu/) under grant No. 739592.; by the Hungarian ED_18-2-2018-0006 grant on a "Research on prime exploitation of the potential provided by the industrial digitalisation" and by the Ministry of Innovation and Technology NRDI Office within the framework of the Artificial Intelligence National Laboratory Program, Hungary.

\section{REFERENCES}

[1] P. Jansohn, Modern gas turbine systems, High Efficiency, Low Emission, Fuel Flexible Power Generation. Woodhead Publishing Series in Energy, 20, 2013, ISBN 978-1-84569-728-0, pp. 8-38.

[2] L. Móricz, Zs. J. Viharos, Trends on applications and feature improvements of ceramics, Manufacturing 2015 Conference, Budapest University of Technology and Economics, 15, No. 2, 2005, pp. 93-98.

[3] Lingfei Ji, Yinzhou Yan, Yong Bao, Yijian Jiang, Crack-free cutting of thick and dense ceramics with $\mathrm{CO} 2$ laser by single-pass process, Optics and Lasers in Engineering, Vol. 46, Issue 10, 2008, pp. 785-790. DOI: $10.1016 /$ i.optlaseng.2008.04.020

[4] Jiyue Zeng, Thomas J. Kim, An erosion model for abrasive waterjet milling of polycrystalline ceramics, Wear, 199, 1996, pp. 275-282.

DOI: $\underline{10.1016 / 0043-1648(95) 06721-3}$

[5] L. Móricz, Zs. J. Viharos, Optimization of ceramic cutting, and trends of machinability, 17th International Conference on Energetics-Electrical Engineering - 26th International Conference 
on Computers and Educations, Hungarian Technical Scientific, Society of Transylvania, 2016, pp. 105-110.

[6] L. Móricz, Zs. J. Viharos, A. Németh, A. Szépligeti, Efficient Ceramics Manufacturing through Tool Path and Machining Parameter Optimisation, 15th IMEKO TC10 Workshop on Technical Diagnostics, Budapest, Hungary, 6-7 June 2017, pp. 143-148. Online [Accessed 2 September 2021] https://www.imeko.org/publications/tc10-2017/IMEKOTC10-2017-024.pdf

[7] L. Móricz, Zs. J. Viharos, Zs. A. Németh, A. Szépligeti, Indirect measurement and diagnostics of the tool wear for ceramics micromilling optimisation, XXII IMEKO World Congress, 3-6 September 2018, Belfast, United Kingdom, Journal of Physics: Conference Series (JPCS), 1065, 2018.

DOI: $10.1088 / 1742-6596 / 1065 / 10 / 102003$

[8] L. Móricz, Zs. J. Viharos, A. Németh, A. Szépligeti, M. Büki, Offline geometrical and microscopic \& on-line vibration based cutting tool wear analysis for micro-milling of ceramics, Measurement, 163, 2020, 108025.

DOI: $10.1016 / \mathrm{i}$.measurement.2020.108025

[9] Xiaohong Lu, Zhenyuan Jia, Xinxin Wang, Yubo Liu, Mingyang Liu, Yixuan Feng, Steven Y. Liang, Measurement and prediction of vibration displacement in micro-milling of nickel-based superalloy, Measurement, 145, 2019, pp. 254-263. DOI: $10.1016 /$ i.measurement.2019.05.089

[10] C. K. Toh, Vibration analysis in high speed rough and finish milling hardened steel, Journal of Sound and Vibration, 278, 2004, pp. 101-115. DOI: $10.1016 /$ i.jsv.2003.11.012

[11] D. E. Dimla, P. M. Lister, On-line metal cutting tool condition monitoring. I: force and vibration analysis, International Journal of Machine Tools and Manufacture, 40, 2000, pp. 739-768. DOI: $\underline{10.1016 / \text { S0890-6955(99)00084-X }}$

[12] J. W. Youn, M. Y. Yang, A study on the relationships between static/dynamic cutting force components and tool wear, Journal of Manufacturing Science and Engineering, Transactions of the American Society of Mechanical Engineers 123, 2001, pp. 196205.

DOI: $10.1115 / 1.1362321$

[13] A. Sarhan, R. Sayed, A. A. Nassr, El. El-Zahry, Interrelationships between cutting force variation and tool wear in end milling, Journal of Materials Processing Technology, 109, 2001, pp. 229-
235.

DOI: $\underline{10.1016 / \text { S0924-0136(00)00803-7 }}$

[14] M. A. Elbestawi, T. A. Papazafiriou, R. X. Du, In-process monitoring of tool wear in milling using cutting force signature, International Journal of Machine Tools and Manufacture, 31, 1991, pp. 55-73.

DOI: $10.1016 / 0890-6955(91) 90051-4$

[15] A. B. Sadat, Tool wear measurement and monitoring techniques for automated machining cells, in: H. Masudi (Ed.), Tribology Symposium, PD-Vol. 61, American Society of Mechanical Engineers, New York, 1994, pp. 103-115.

[16] A. B. Sadat, S. Raman, Detection of tool flank wear using acoustic signature analysis, Wear, 115, 1987, pp. 265-272. DOI: $10.1016 / 0043-1648(87) 90216-X$

[17] H. K. Tönshoff, M. Jung, S. Männel, W. Rietz, Using acoustic emission signals for monitoring of production processes, Ultrasonics, 37, 2000, pp. 681-686. DOI: $10.1016 / \mathrm{s} 0041-624 \mathrm{x}(00) 00026-3$

[18] I. Szalóki, Programming trochoidal trajectories in Microsoft Office Excel, ÓE / BGK / Cutting technology computer design task, Budapest, 2012., pp. 30.

[19] W. Shao, Y. Li, C. Liu, X. Hao, Tool path generation method for five-axis flank milling of corner by considering dynamic characteristics of machine tool, Proc. of Intelligent Manufacturing in the Knowledge Economy, Procedia CIRP 56, 2016, pp. 155160 . DOI: $\underline{10.1016 / \text { i.procir.2016.10.046 }}$

[20] B. Warfield, Complete Guide to CAM Toolpaths and Operations for Milling in 2020, Edition. Online [Accessed 1 August 2020]. https://www.cnccookbook.com/cam-features-toolpath-cnc-restmachining

[21] M. S. H. Bhuiyan, I. A. Choudhury, M. Dahari, Y. Nukman, S. Z. Dawal, Application of acoustic emission sensor to investigate the Frequency of Tool Wear and Plastic Deformation in Tool Condition Monitoring, Measurement, 92., 2016., pp. 208-217. DOI: $\underline{10.1016 / \text { i.measurement.2016.06.006 }}$

[22] Zs. J. Viharos, K. B. Kis, Á., Fodor, M. I. Büki, Adaptive, Hybrid Feature Selection (AHFS), Pattern Recognition, 116, 2021, art. 107932.

DOI: $10.1016 /$ i.patcog.2021.107932 